\title{
Evolution, Complex Systems and the Dialectic
}

\author{
by \\ Peter Knapp \\ Villanova University \\ email: PKNAPP@EMAIL.VILL.EDU
}

Cite: Knapp, Peter. (1999). "Evolution, Complex Systems and the Dialectic." Journal of World-Systems Research http://jwsr.ucr.edu/ 5: 74-103.

(c) 1999 Peter Knapp.

[Page 74]

Journal of World-Systems Research

\begin{abstract}
The status of large scale historical macrotheories is contested both in world-systems theory and in sociology as a whole. I distinguish three types of such dynamic models: evolutionary models, systems models and dialectical models. I define dialectical models as a family of complex systems models characterized by positive feedback (self-reinforcement or auto-catalysis). Such models lead to processes of accumulation and polarization, leading to system crisis. The games of Monopoly and Risk provide popular examples. This paper investigates the dynamic properties of three examples of such models: Myrdals model of cumulative causation; Collins's models of Marxian transformations and geopolitics; and Chase Dunn and Hall's iterative model of world-systems transformations. A combination of evolutionary, complex systems and dialectical analyses has considerable overlap with chaotic, far-from-equilibrium types of models and with analyses of complex adaptive systems. Such discontinuous, nonlinear dynamic models show great potential for solving problems of dynamic analysis both within world-systems theory and within sociology as a whole.
\end{abstract}

\section{Introduction}

Within sociology as a whole, the aim of constructing predictive macro-theories has an ambiguous place, and this ambiguity is even more marked within worldsystems theory. The distinctive concepts of sociology w ere quarried out of nineteenth century macro-theories, particularly those of Marx, Durkheim and Weber (Knapp, 1994), and their theories rested on the larger mass of historical and evolutionary macro-theories by figures such as Bagehot, Comte, Condorcet, Ferguson, Hegel, Maine, Morgan, SaintSimon, Spencer and Toennies. But today, subdisciplines concerned with social change, such as historical sociology, are relatively isolated from the mainstream of sociological analysis, which concentrates on such contempo rary institutional structures as formal organization, the family, or crime and deviance, taking larger institutional dynamics for granted. This means that for many sociologists, subdisciplines concerned with social change, such as the Political Economy of World-Systems are treated as relatively irrelevant to the main theories and the day to day work of sociological analysis. Dynamic 
large-scale theories of social change are more prominent within world-systems theory. But approaches to world-systems aiming at a theory of large scale dynamics are in tension with approaches that are skeptical about the possibility of any such theory, and treat the large scale dynamic as a given context for the analysis of particular historical configurations.

Large scale theories of social change are often driven by the simple projection of long term secular trends. Some secular trends appear to characterize the demographic, technological and economic spheres, usually conceived by Marxists as parts of the material base. With various oscillations, there has been an inexorable rise in the world's population, and long term increases in literacy, science, technology, productivity and economic production, with manifold further consequences -- increase in transportation, communication and connectedness of the world's population. There has been a rise in the size and complexity of organizations and political units. Secular trends of this kind have been one of the roots of evolutionary theories in sociology. Such theories often attempt to state the implications of such secular trends for the political or cultural spheres (Knapp, 1994). Such trends seem to some theorists to enable other changes in spheres such as inclusive citizenship, ethnic tolerance, gender equality or political democracy and to necessitate other developments. The Marxian conception of the expansion of the forces of production, and their dialectical fettering by the relations of production (Cohen, 1978) formulated one model of these linkages. The evolutionary conception of modernization, differentiation and modern values, formulated another.

[Page 75]

Journal of World-Systems Research

Sanderson $(1990 ; 1997)$ has stressed the resources of evolutionary theory. He acknowledges that many evolutionary theories are teleological, progressivist, overly endogenous, use a specious (functionalist) concept of adaptation, lack an adequate concept of human agency, and impute too much directionality to human history. However, he argues that these flaws are accidental rather than necessary characteristics of evolutionary theories. He reports that most sociological respondents believed that evolutionary theories are sound in principle, but in need of improvement (Sanderson, 1997). While few sociologists believe that evolutionary theories are undeserving of criticism, only about one third believe that they should be abandoned.

The growth of technology, science, complexity, literacy, urbanism or productivity opens up possibilities and imposes imperatives on changes in economic, political, cult ural and social relations. Social, political and cultural structures which were viable in a prenuclear age or in an age when primitive transportation and communications could slow the spread of epidemic diseases, may be entirely non-viable today. Fundamental disagreements about historical development and social change hinge on such possibilities or imperatives. The abolition of feudalism or of slavery suggest irreversible, directional tendencies. This does not imply philosophical, teleological or ontologic al necessity, and it 
is perfectly compatible with the notion that a natural or social catastrophe might reverse millennia of development. However, directional changes are not a random walk. They reflect an intrinsic dynamic which, for good or ill, will continue as long as the structural sources of that dynamic persist and are not counteracted.

This paper will analyze a family of models of evolution and transformation that are based on positive feedbacks. Any process that reinforces or feeds on itself can be described as a positive feedback loop, and such processes tend to produce a secular trend. The positive feedback loop is one of the simplest and, arguably, most pervasive of feedback structures. It characterizes autocatalytic or self-reinforcing processes. Positive feedback is the natural model for processes of accumulation.

[Page 76]

Journal of World-Systems Research

Positive feedback processes also have an intrinsic tendency to reach a limit and they often are characterized by path dependency, instability and amplification of shocks. Thus, such processes and models based on them are characterized by catastrophic discontinuities, and by chaotic, far-from-equilibrium dynamics (Hallinan, 1997; Wallerstein, 1997). Such processes often generate tendencies to ward increased inequality and polarization, especially when applied to control of scarce resources such as wealth or land, power or influence.

The archetype of such processes are those driven by "The Matthew Principle" - "To him who hath shall be given and from him who hath not, shall be take away even what he hath," from the parable of the three servants, Matthew 25:29 (Merton 1973; Cole and Singer 1991; Knapp et al, 1996). There are many social processes in which possession of one resource makes it easier to acquire others. The game of Monopoly provides a clear illustration of the systemic dynamic of accumulation, increased rents, polarization and increased inequality leading to the collapse of the game when all players but one are wiped out. The game of Risk, based on the accumulation of territories as a source of armies, provides an isomorphic geopolitical illustration. Such processes tend to produce increased inequality as well as polarization, and thus they are natural models for Marxian dialectical processes and transitions (See Figure 1). 
Figure 1: Basic Structures of Accumulation

Figure 1A: The Basic Positive

Feedback Loop of Accumulation

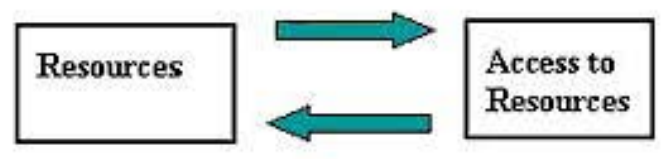

Figure 1B: Capitalist Political

Economy as a Game of Monopoly

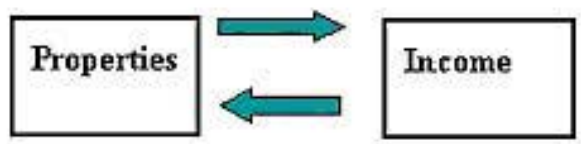

Figure 1C: Nation State

Politics as a Game of Risk

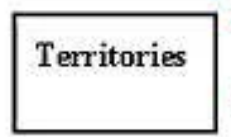

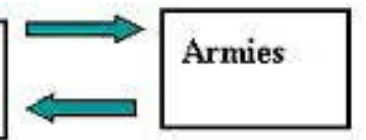

[Page 77]

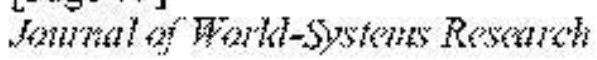

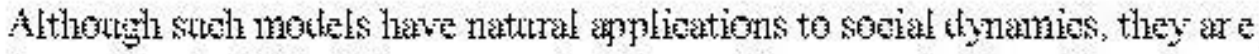
"nonrectrsive." Variables onnot be arranged in a causial orker without loops. Most of our

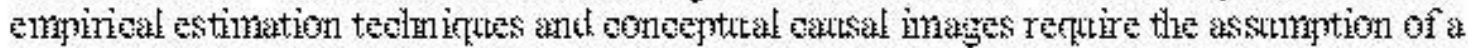
reetrive malel. Nevertheless, the kinds of empirieal and theoretieal froblems which we now face may require tos to think in nonrextrsive tents, and in toing 5 , it will be the fut to employ a form of dialedieal analysis.

\section{Evolutionary Theory}

Evolutionary theory has been an essential joint of reference for maero-sedal theory. The

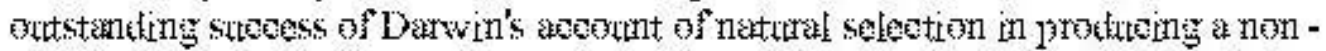

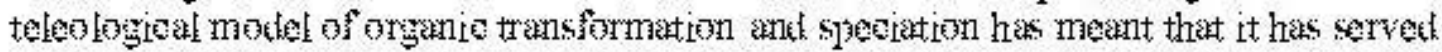

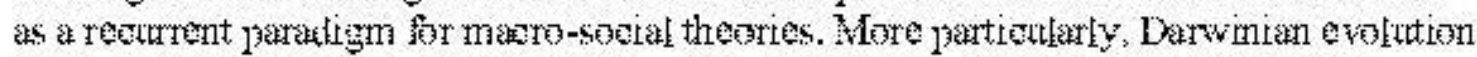

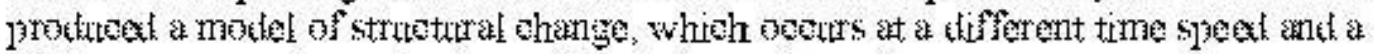
different joess fom the observable actions of organisms.

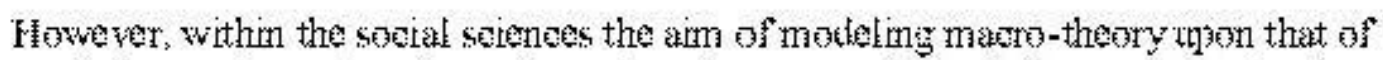
evolutionary theory has always been shanjy eontested. Evolutionary theory has been closelytiad to Soeial Darwinism, which has itoologieal and theoretioal implieations

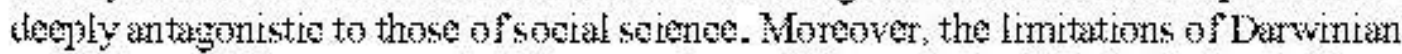
evolution as a theory, even in its home shome of the analysis of biological variation, are rem fored in the soinl sphere, where there are no mechanisms dired ly analogers to

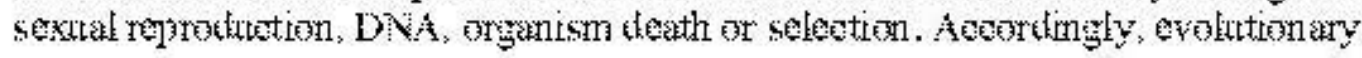


models of social change are often diffuse analogies which give no theoretical explanation of the long term secular trends.

[Page 78]

Journal of World-Systems Research

One of the great virtues of Sanderson's (1991) analysis was to show the interconnection between theories of macro social change and specific, local sociological theories. Sanderson (1997:94) has rightly stressed the fact that the classic sociological theorists often held evolutionary assumptions. He mentions Durkheim's Division of Labor in Society, but it would be equally correct to stress evolutionary themes in Marx, Weber, Mead, Spencer or Park. The fact that early sociologists were concerned to explain powerful, long run directional transformations mean that they had to come to terms with Darwin's evolutionary theory. For example, Marx offered to dedicate Capital to Darwin and the Afterward to the first German edition described the dialectical method in terms of evolutionary theory. There, Marx gave an extended quote from a Russian review which had underscored the aim of establishing objective laws of motion which operate independently of human volition. The review had asserted that there is a law of the connection between political-economic phenomena at any time, and that there are laws of variation governing their development and transition. The review continued that Marx,

"proves, at the same time, both the necessity of the present order of things and the necessity of another order into which the first must pass over;.... The old economists misunderstood the nature of economic laws when they likened them to the laws of physics and chemistry. A more thorough analysis of phenomena shows that social organisms differ among each other as fundamentally as plants or animals... The scientific value of such an inquiry lies in the disclosing of the special laws that regulate the origin, existence, development and death of a given social organism and its replacement by a higher one." (Marx 1974[1887]: 17-9)

[Page 79]

Journal of World-Systems Research

Marx adopts the reviewer's view that the aim and method of Capital is like that of biological evolutionary theory, and he identifies this aim and method as that of the "dialectic," commenting,

"Whilst the writer pictures what he takes to be actually my method, in this striking and [as far as concerns my own application of it] generous way, what else is he picturing but the dialectical method." (Marx ibid.) 
This virtual identification of dialectic with the method of biological evolutionary theory raises a number of questions, to which we shall return in the fourth section of this paper. However, it is evident that Marx, as well as all the other classical sociological theorists, whatever their admiration for some aspects of Darwinian theory, also maintained a distance from it because of its ideological affiliations, because of the limitations of Darwinian theory as a theory of long term change, and because of the dis-analogies between biological and social evolution.

During the late nineteenth and early twentieth centuries, the most influential evolutionary social theories were those associated with Spencer, Darwin, Galton and Sumner, based on conceptions of biological inequality and liberal individualism. World War II, the Holocaust and the New Deal were an abyss for this kind of evolutionary social theory, and the forms of evolutionary theory which reappeared after World War II disassociated themselves from biological assumptions of European genetic superiority. Nevertheless, there remained powerful historical and logical connections between evolution, biological natural selection and justifications of individual and group inequality. Evolutionary theories tend to be drawn to liberalism by a kind of hidden gravitational attraction. And this connection is important because of the resurgence today of neoracist evolutionary theory (Rushton, 1995; Levin, 1997; Jensen, 1998; Taylor 1998).

[Page 80]

Journal of World-Systems Research

Moreover, even aside from its ideological affiliations, Darwinian theory has limitations as a theory of long run changes, even in its home sphere. The assumption that mutations are random, that modifications build on each other and that adaptation is relative to a given environment means that there is no reason to suppose that an evolutionary process, if repeated, would produce the same outcome. Natural history cannot ground predictions. While the theory of natural selection provides a framework for analyzing the process by which long run evolutionary trends came about, there is doubt whether the gradual accretion of adaptive changes provides a sufficient or an adequate account. Gould (1989) has stressed the discontinuous rates of change, with cascades of evolutionary modification, punctuated with mass extinctions. A mammal is "higher," "more adapted," or "more complex" than a cockroach only in a value-laden, ambiguous and undefined sense. Levin \& Lewontin (1985) have stressed that what evolves is not an organism, subject to a fixed and given environment, but an ecosystem. Theorists of complex adaptive systems such as Kauffiman (1993), have stressed that mutual interconnection and adaptation is subject to "red queen effects" (from the scene in Alice In Wonderland in which one must run to stay in place). If one set of organisms is developing massive attack claws and teeth, while another set develops increasingly massive defense armor, then each may be more "adapted," so that organisms without the attack or defense features will be weeded out. But they are adapted to each other and to a specific environment; probably "adapted-in-general" is a nonsense category. Their adaptation, like that of the 
nation state as a war making machine, does not mean that they are adapted to other environments or threats, such as climatic changes or disease.

[Page 81]

Journal of World-Systems Research

Moreover, even if the process of natural selection were an adequate and sufficient account of biological evolution, there are powerful differences between biological and social evolution. Processes of social, cultural and political change are often Lamarkean rather than Darwinian and operate on an immensely shorter time scale. Van Parijs (1987) shows that even restricting consideration to the two processes of blind selection and of reinforcement (and diffusion), the combination of local equilibria and interaction may produce a highly discontinuous, unpredictable process. Sanderson detaches evolutionary theory from progressivism and teleology at the cost of making it nonpredictive, by arguing that societies are not adapted, but individual behavior is adaptive. However, this risks merely saying that people do what they do because it seems to them like a good idea at the time. It is unclear that this generates a theoretical explanation of any long run directional trends, particularly consequential material trends.

\section{Complex Systems}

A central insight of sociological theory, in opposition to the liberal individualism typified by Spencer, was that social structures have properties which are not easily or obviously a function of the individuals who are members of those social structures. The dynamics of a hurricane are not well-analyzed in terms of the trajectories and dynamics of individual rain drops (Mahew, 1980). Social structures may reproduce or perpetuate themselves independently of the awareness and intentions of individuals. One of the basic attractions of biological evolution as a model of large scale change was the promise to provide a model of macro-structural change. Similarly, one of the basic insights of world systems theory, in opposition to modernization theory, was that the structure of the world system exists and reproduces itself independently of the position of various societies, states and regions within it.

[Page 82]

Journal of World-Systems Research

During the twentieth century, systems theories have been an important body of analytical techniques that are relevant to such holistic properties of structures. Since its origin in engineering analysis, systems theory has developed into a number of heterogeneous bodies of analysis with separate journals, methodologies and almost non-overlapping literatures. For example, general systems theory was an ambitious programs for a general theory of all holistic structures (Von Bertalanffy, 1968). It inspired subsequent attempts 
to model system needs of organizations on those of all living systems (Miller, 1995). Cybernetics (Weiner, 1965) generated a vast array of analyses of information systems. Systems dynamics constitutes a family of techniques for simulating feedback models in the investigation of organizations, urban or ecological processes (e.g. Forrester 1969; 1971; Collins, 1995) Systems analysis and operations research constitute a wide variety of ways of breaking down an organizational structure or process (Cortes, 1974). These and similar bodies of theory have demonstrated the possibility of powerful counterintuitive dynamic effects of system structure, and in the past decades, the technical capacities of computer modeling have led to a powerful explosion of simulations of complex system dynamics (Collins, 1995; Bar-Yam, 1998).

The dynamics of a system can always be represented in at least two ways: as a set of causal relations operating between parts, and as a trajectory in a phase-space. Even very simple deterministic nonlinear systems may generate non-repeating, unpredictable trajectories that exhibit discontinuous shifts from one region to another of the phase space (Lewin, 1992).

The potential for constructing dynamic holistic models of social structures have been one of the main promises of systems theories. However, those promises have been largely unfulfilled. Burns and his collaborators (Burns \& Buckley 1976) distinguish "morphostasis," systemic processes operating within a given structure, maintaining that structure, and "morphogensis" the kinds of processes operating to transform the structure. In principle, both kinds of processes can be investigated with systems methods, concepts and simulations. In practice, systems models have concentrated almost exclusively on "morphostasis" and have great difficulty dealing with the genesis and transformation of systems. Dynamic simulations that treat the structures and relations as given often assume away precisely those processes that most sociologists would consider "dynamic." Empirical analysis of (nonrecursive) models with feedbacks raises formidable technical problems. For example, such feedbacks will violate assumptions of uncorrelated error terms, which allow simple least squares estimation, and they will often produce identification problems, which make empirical estimation of causal effects impossible. While there are technical solutions to many of these problems, such as two stage least squares estimation techniques (Berry, 1984; Brown, 1995), they are inconvenient and make demands for data and rigorous theory which we often lack.

[Page 83]

Journal of World-Systems Research

The result of these problems is that systems models are often static analyses by stipulation. A set of components and of causal forces is assumed and treated as given; their simulation is not connected to empirical evidence that the causal forces are as assumed in the model. Such simulations may be useful in showing implications of theoretical assumptions or the sensitivity of a dynamic to variation in some component parameter (Hanneman and Collins, 1987; Collins, 1995). Sometimes simulations show 
that no plausible variation in some inputs or causal connections makes much difference to the operation of such system. Forrester constructed well-known simulations suggesting that all the currently considered solutions to some problem were bound to fail (1969; 1971), either because the proposed solutions generate feedback increases in the initial problem, or because alternative paths make changes in some inputs or par ameters ineffective.

Thus, even without quantitative estimation, the qualitative structure of causal relations, is often far more important than the quantitative size of its component parameters. For example when variables are part of a mutually reinforcing complex, sorting out the quantitative effects of any one of them is often both ferociously difficult and practically irrelevant. Often, what is important dynamically is the net mutual reinforcement of the complex, which may lead to qualitative system dynamics such as path dependence, instability and amplification of small differences in initial conditions. Moreover, systems of positive feedback often have two properties which are extremely useful in explaining structural change: they often produce a secular trend, and they often produce increased inequality and polarization. In both cases the dynamic reaches a limit, either external or internal. We shall consider three examples of systems of positive feedback: Myrdal's analysis of cumulative causation, Collins's models of Marxian crises; and Chase-Dunn and Hall's iterative model of world-systems transformations. Each of them can be understood as an evolutionary dialectical process.

[Page 84]

Joumal of World-Systems Research

a) Myrdal: In An American Dilemma (1944), Myrdal argued that minority group disadvantages encourage white racism (e.g. white supremacy, segregation and stereotyping) which reinforce minority disadvantages. Myrdal developed the conception of group advantages or disadvantages as a mutually reinforcing, auto-catalytic process. He suggested that group characteristics such as mean education, job skills, percent employed, income, wealth, health, credit rating, political influence, marital stability, or law-abidingness are mutually reinforcing. Advantages promote other advantages; disadvantages promote other disadvantages. The result is a vicious cycle that tends to produce greater inequality, polarization and segregation.

Myrdal's Nobel prize was based on the idea that cumulative causation (both as vicious cycles of poverty and as beneficent cycles of development) is central to the analysis of development and institutional transformation (1968; 1970; Agresano, 1997). The mutual reinforcement of advantages or disadvantages, often called the Matthew Effect in sociology (Merton, 1973), operates at several levels of analysis (Knapp et al. 1996). An individual's characteristics may affect his or her life chances; they may affect aspirations and identity; and the characteristics of an individual's neighborhood, network, family, racial or ethnic group may affect the individual's life chances, either directly or by 
influeneing the responses of others. A whole societymay have atvantages or

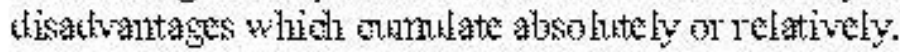

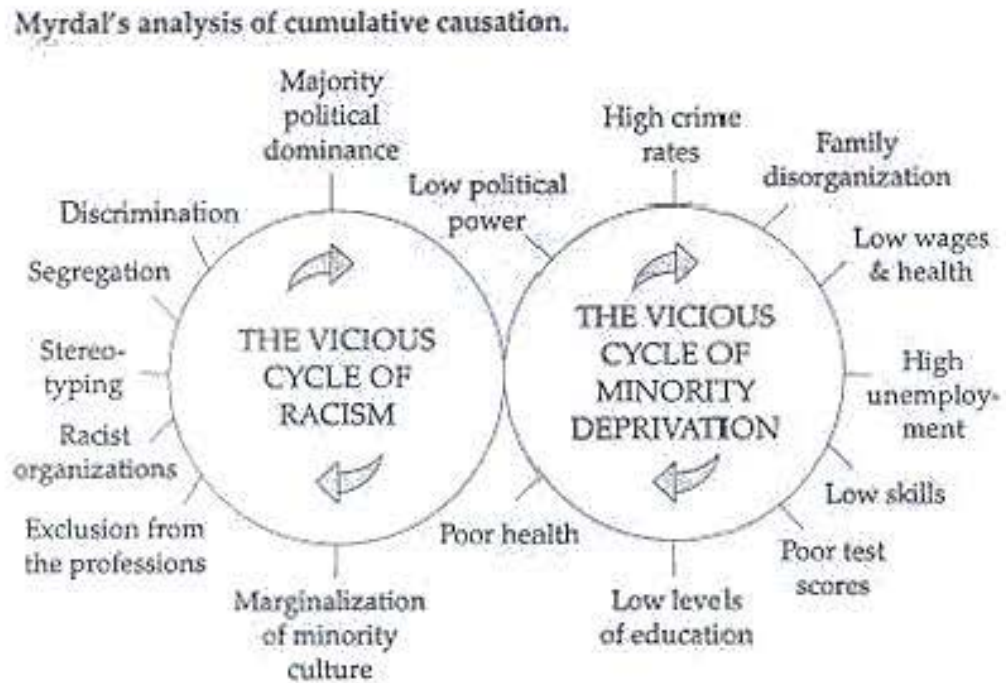

Note; These variables have been represented as two victous cycles. All the interconnections of each cycle and the further interconnections between them have not been represented. But a structure of cumulative causation is defined as one in which each characteristic is reinforced by and reinforces each of the others.

In Figne 2, the two chreses remesent the mutually reinforeng omm lexes of majority

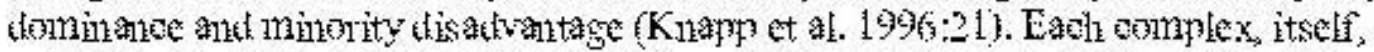
consists of a mass of thatwantages and or mizileges that are muthally reinforeing. Beculse eadi element reinfores the others in the connolex, in the alusene of other fores

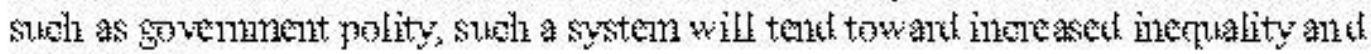
polarization.

[Page 55$]$

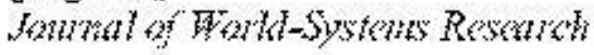

Myrdal stresset that sud feetload woles of atwantage or disatwantage tent to be path

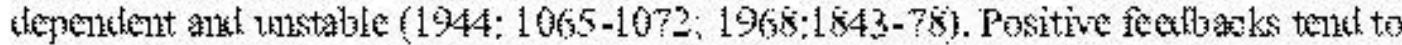

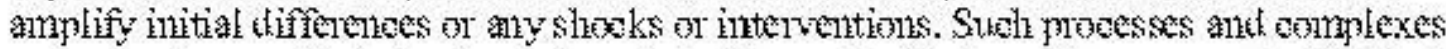
are pervasive, and their tentenoy to polanization and pathe dependenoy generates the kinet

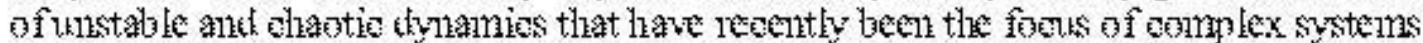

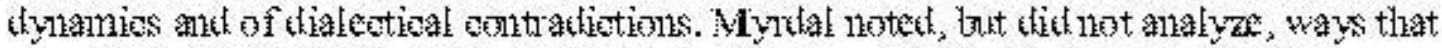
processes of mobilization ant mass adtin can be expected to further amplify the

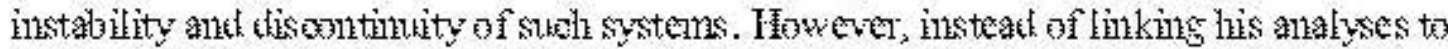

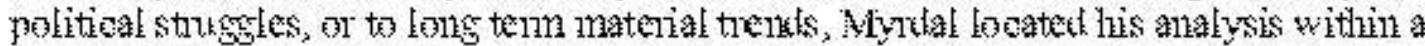
finetional framework, afflibating his analysis to the "value memise" of the "Amenoun

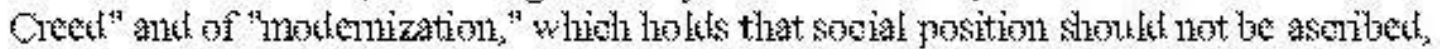


and which generates a "dilemma" between a value commitment to an open society and the dynamic of unequal life chances and segregation generated by cumulative causation. A similar functionalism deformed his developmental economics.

b) Collins: A second example of a systems model of social transformation is Collins's (Hanneman \& Collins, 1987; Collins, 1995) models of revolutions and of the welfare state. Collins, a Weberian conflict theorist, argues that most aggregate social theory neglects dynamic models in favor of comparative statics (Collins 1995) The great virtue of Marx's theories, Collins argues, is that they were dynamic, while Weber's models, including those of the prerequisites of rational capitalism, are ideal-typical comparative static analyses. Collins's simulation of the Marxian model of capitalism uses the microDYNAMO program (Hanneman, 1988) to explore its theoretical sensitivity to assumptions about the size of some of its parameters.

[Page 86]

Journal of World-Systems Research

The central model is related to the core MCM' model from Capital. Profit-making leads to the increasing organic composition of capital as well as to the concentration of capital, the decline in the number of capitalists and an increase in the rate of unemployment (the reserve army). In the standard run, this leads to uncreased unemployment, depression, inequality, and the erosion of the power base of capitalists and loss of state power -- the classic scenario of Marxian revolution. The further dynamics of Collins's model flow from its assumption that, since capital accumulation is funded out of profits, the loss of state power by the capitalist class halts capital accumulation, leading to the stagnation of the economy, and the further rise of unemployment. Thus, Collins and Hanneman's second model of the post-revolutionary situation avoids this stagnation by having the state function as an organ of planning and capital accumulation - leading to a statemanaged economy. But what is possible in the post-revolutionary situation, Collins and Hanneman suggest, is also possible under capitalism, and so they construct a third model, in which the rise of unemployment and capital concentration is avoided by the development of a welfare state.

Thus, Collins produces a single model of accumulation, whose developmental dynamic branches into three trajectories: revolution followed by collapse; revolution followed by state-planing; or avoidance of revolution by a welfare state. The concepts are unremarkable; the parameter specifications are debatable; the trajectories do not appear to exhaust all possibilities. But what is important is that the analysis derives substantively important alternative outcomes often conceived as representing fundamentally different causal structures, as branching paths from the same model, given relatively small changes in some parameters.

The central divergences of the models result from shifts in state power, and the authors do not elaborate their assumptions with respect to this parameter. The substance of the 
analysis requires further investigation. A fundamental virtue of the model is that it shows that reasonable assumptions about ways that unemployment and inequality result from the self-reinforcing cycle of capital accumulation and about the impact of unemployment and inequality on political mobilization make it possible to develop plausible dynamic models of social transformations producing substantively interesting diverging trajectories.

[Page 87]

Journal of World-Systems Research

It is interesting that Collins fails to relate this endogenous system model to the intersocietal, geopolitical model that Collins claims is the central explanation of the transformation and dissolution of the Soviet block (Collins,1992). In that model, expansion arises from the feedback loop in which the territorial size of the conquering state leads to greater resources, which leads to military advantage and regime legitimacy. The expansion hits limits (represented by negative feedback loops) when the expanding state attains a central position (king of the mountain, eliminating marchland advantage) and to logistical overloads (1992: 1560). Collins maintains that in the 1970s, the former Soviet Union was reaching those limits, leading to unraveling and collapse. He suggests that the geopolitical model, at the largest time scale, can be usefully connected to internal dynamic models, such as Tilly's, in which military success leads to intensive resource extraction, which leads to state organization which leads to military success .

The self-reinforcing character of Collins's geopolitical arguments (1992) can be simply represented by a positive feedback loop of domination, directly analogous to the positive feedback of advantage and accumulation. Control of population, coercive reso urces or strategic areas may help a power to acquire further resources. The game of Risk in which territories yield armies, and armies yield territories, is a simplified archetype of this dynamic. Myrdal stresses that the loop of cumulative causation is unstable -- the way up is the way down. The amplification of advantages generates a beneficent cycle, but if anything brings that process to an end the amplification of deficits will generate a vicious cycle (unless one happens to end on the knife edge of an unstable equilibrium). The process of domination is unstable and path dependent in the same way. The accumulation loop generates inequality, which is reinforced by the transfers of resources from the poor to the affluent, and the process of domination should generate power inequality and concentration of power in the same way.

[Page 88]

Journal of World-Systems Research

c) Chase-Dunn and Hall: A third example of a systemic model of social transformation is the iterative model of world-systems transformation developed by Chase-Dunn \& Hall 
(1997). A central construct of world-systems theory has been the self-maintaining reproduction of inequality between core and periphery, which produces a powerful dynamic over the last 500 years. The system has depended i mportantly on the incorporation of new groups and new areas into the world economy. Those processes inexorably approach limits when $100 \%$ of the world's population and territory is incorporated. At those limits the irresistible force of incorporation hits the immovable object of global limits, producing systemic crises. An idiographic answer to the question what happens next is that system dynamics can only predict that there will be a crisis, but outcomes are necessarily invisible. A more theoretical approach extends the theoretical definition of world-systems from the modern, global, capitalist world system to prior world-systems

Though not global, they were world-systems in exhausting or nearly exhausting the reach of commercial, political and cultural networks. Thus they constitute a reasonably large universe of inter-societal systems that came into existence, expanded and then been merged or incorporated into larger systems. Chase-Dunn and Hall's analysis of the dynamics governing the "rise and demise" of such systems marries a theory of semiperipheral institutional innovation to the model of circumscription developed by Carneiro, Harris, and Cohen (Chase-Dunn \& Hall 1997; Sanderson, 1995). The theory of semiperipheral innovation has roots in Trotsky's concept of uneven and combined development, Gershenkron's analysis of the "advantages of backwardness," Service's distinction between adaptation and adaptivity, and Quigley's concept of the institutionalization of an instrument of expansion (Chase-Dunn \& Hall 1997: 78-82). The dominant core states are institutionally inflexible because of the sunk costs of commitment to institutional forms which are the basis of their core position. Peripheral areas are also locked into the existing institutional structures both by their poverty and by ties to the core, but some semiperipheral societies are in a position where it is possible to make structural innovations and to implement them.

[Page 89]

Journal of World-Systems Research

The core of Chase-Dunn and Hall's model of political circumscription is the positive feedback loop connecting hierarchy formation and intensification. Hierarchy formation refers to "increases in socially structured inequalities within or among societies (e.g. class formation, state formation, or empire formation)" (Chase Dunn \& Hall 1997:101-3), and intensification refers to "technological innovations and the adoption of intensified production practices" (ibid.). Hierarchy and intensification are formulated abstractly, to apply to different modes of accumulation in different epochs. In Marxist terms, they are analogous to the relations and the forces of production. Chase-Dunn and Hall (1997: 102) suggest that similar dynamics repeat themselves (iterate) in the transformations of "modes of accumulation." Several aspects of the model highlight the characteristics of positive feedback models of accumulation and domination. 


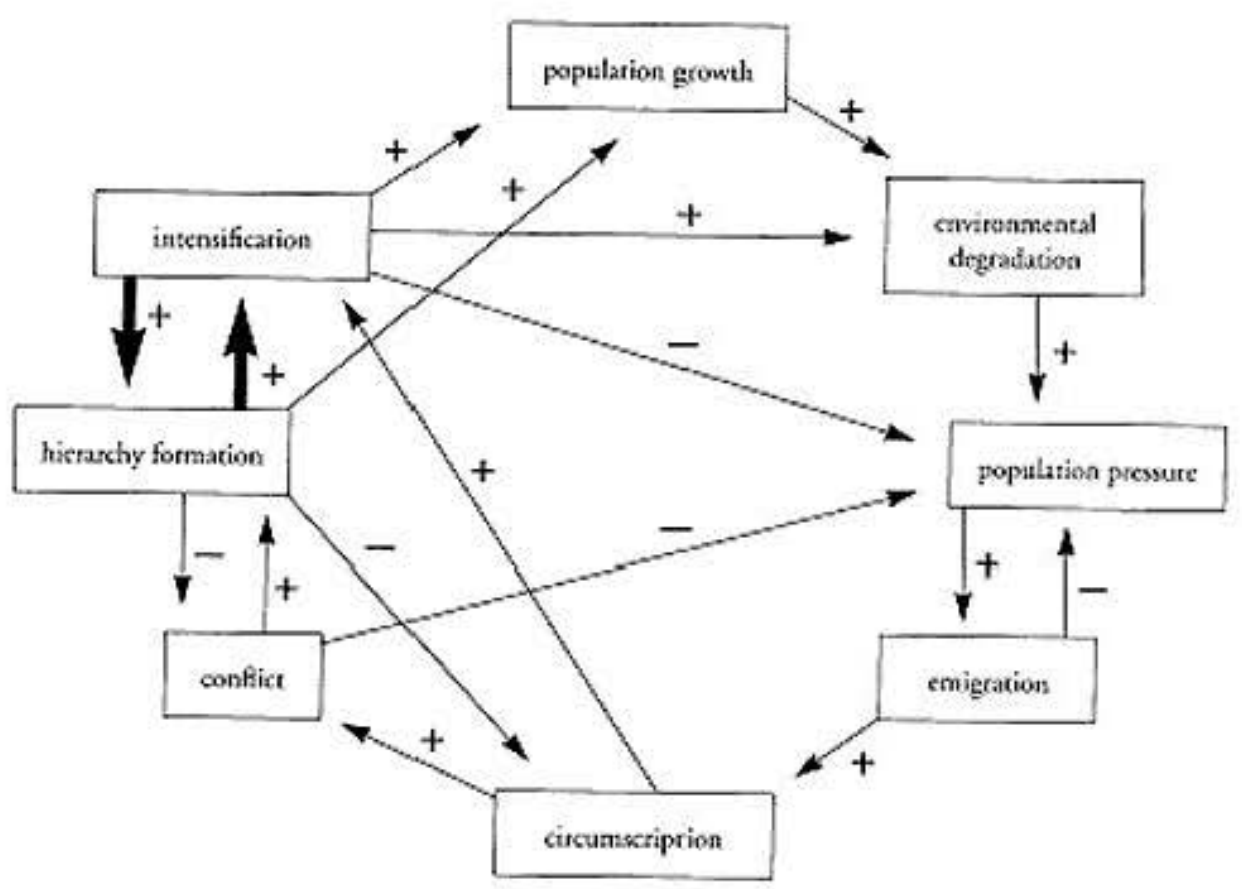

FIGURE 6.1 The Pogulation Pressure/latensification/liceardly Formation Modd

This molel contains two positive feetlokek loofs:

- the tíght and jowerfut in teration between herachy formation and intensiffoation, ant.

- the great positive loop involving the other six warkables ( ignoring the five negative paths.

The negative paths operate as a set of (temporary) safety wates, reliening portation presstre.

[Page $\odot$ ]

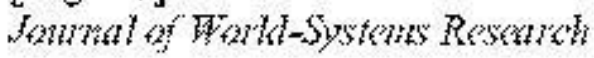

A positive feethack loop tents to expand watil it hits a limit. One of the simplest way of

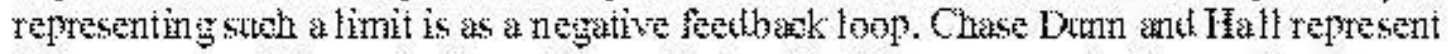
the proesses of hierardy formation and intensifoation as omneded to negatine

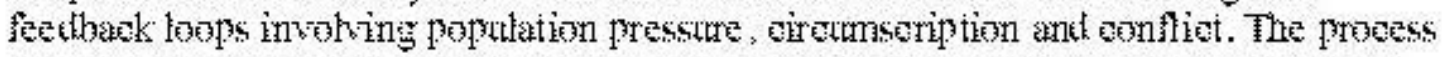

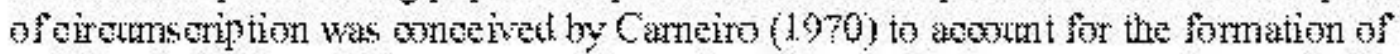

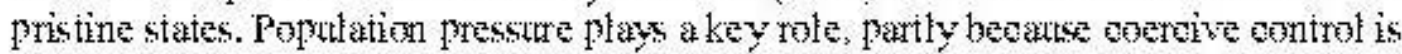

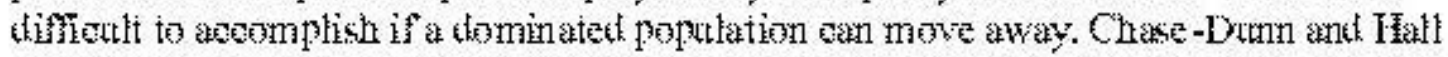

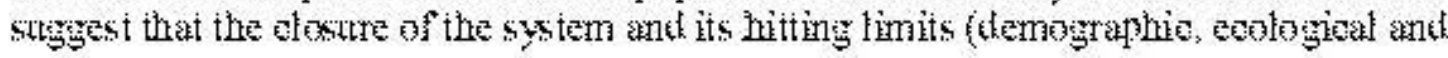


its ability to handle internal and external conflict) are central to other transformations of world-systems, as well as to state formation. It is the circumscription of the core powers benefiting from a given mode of appropriation that opens opportunities for semiperipheral innovation.

I cannot pursue this analysis further here, except to make one remark about the mutual reinforcement of hierarchy and intensification in relation to circumscription. We have suggested that hierarchy and intensification are not only mutually reinforcing, but that each of them constitutes a self-reinforcing process of accumulation/domination with intrinsic limits. The accumulation of capital and increase of productivity is analogous to Monopoly; the accumulation of power and domination to Risk. But of course, the economy does not always polarize as in Monopoly; and conflict within the political state system does not always end in world empire. If there are intrinsic tendencies of such feedback loops to do so, this raises the question what counteracts those intrinsic tendencies. A central insight of world-systems theory is that it is the linkage of the two processes; a central issue of the circumscription model in the case of the circumscription of a world economy, is the breakdown of that linkage.

[Page 91]

Journal of World-Systems Research

\section{Dialectical Theory}

Traditionally, Marxists have dealt with the problems posed by evolutionary change, complex systems and system transformation by using concepts of the dialectic. However, the consolidation of a world-view and analytic strategy in opposition to mainstream liberal social and political thought sedimented a considerable amount of ideological baggage onto conceptions of dialectics. Even if we exclude the dialectics within classical Western philosophy, "dialectic" refers to a number of different kinds of analysis done by figures such as Hegel, Marx, Engels, Lenin, Loquacious, Stalin, Mao Zedong, Gramsci, Adorno, Habermas, and Bhaskar . It is doubtful that any single schema could welldescribe the key features of all of them.

We saw that Marx identified "dialectic" with the view that everything is changing and finite -- nothing lasts forever. Engels characterized substantive dialectic as a process,

"the great basic thought that the world is not to be comprehended as a complex of readymade things, but as a complex of processes, in which the things apparently stable, no less than their mind images in our heads, the concepts, go through an uninterrupted change of coming into being and passing away, in which in spite of all seeming accidentality and of all temporary retrogression, a progressive development asserts itself in the end..." (Engels 1888). 
[Page 92]

Joumal of World-Systems Research

It is possible to distinguish two broad branches of dialectics that are complementary and interrelated: epistemological (concerned with the transformation of concepts) and ontological or substantive (concerned with objective transformations of "things," Knapp \& Spector, 1991). They are interrelated partly because the development of concepts and theories can be understood as a natural social process or practice. Cultural categories build on each other and develop by a process similar to cumulative causation and positive feedback. As a theory of knowledge, dialectics often refers to a circular or nonfoundational epistemology (Rockmore, 1986), based on a feedback model of practice. Here, we lay aside conceptual and epistemological aspects of dialectics to focus on substantive processes.

Traditionally, Marxists have approached substantive dialectics in terms of a family of concepts derived from Hegel, including negation, contradiction, diremption, limit and sublation. Such concepts have a natural affinity with positive feedback dyna mics. While neither Hegel nor Marx were "systems theorists," Hegel had an acute sense of the ways in which cultural, political, social and historical arrangements and processes were often selfreinforcing. He also recognized that such processes tended to p roduce accumulation and polarization and to hit limits, so that they become self-destroying by the same dynamics which had been self-reinforcing. Marx admired and developed these ideas, and later Marxists have applied them in a host of ways.

More generally, Marxists have approached substantive dialectics as a focus on process. Anything whatever is changing; it is not only what it is but also what it is becoming. Anything whatever is finite; it will not last forever; it allows a "historical section" which traces its origin and self-maintenance to its demise.

[Page 93]

Journal of World-Systems Research

This clearly was the central idea that Marx ascribed to biological evolution, as remarked above. It is because any thing is interconnected with everything else that it is as it is; and so these interrelations can be defined as part of its essential being. And this inclusive or systemic conception of the thing to be explained leads to the centrality of the concept of contradictions as the basis of an explanation of developmental dynamics and developmental possibilities (Knapp \& Spector, 1991). Thus, Marxist treatments usually emphasize interconnection, holism, transformation, finiteness, accumulation, polarization, limits and contradiction. 
This essay has stressed that there is an affinity between these aspects of dialectic and the dynamics of complex systems, particularly systems of positive feedback. Not all analyses of positive feedback are dialectical; not all dialectical analyses concern positive feedbacks; but most systems of positive feedback are highly likely to display dialectical properties.

Systems of positive feedback are simple and arguably pervasive. One example of this process is an accumulation loop (Monopoly) in which control of economic resources leads to further resources. Another is the process of domination (Risk) in which control of power or coercive resources generates further power. Both processes are recursive and must ordinarily be analyzed as holistic systems, and both tend to be unstable and path dependent and to generate inequalities. The tendency to generate inequalities is one reason that the concepts of contradiction and conflict are apt; the fact that their expansion tends to bring them into collision with limits (such as ecological carrying capacity) is another.

[Page 94]

Journal of World-Systems Research

Thus, I would agree with the enigmatic opening sentence of Ekhardt's essay, "A Dialectical Evolutionary Theory of Civilizations, Empires and Wars."

A "dialectical evolutionary theory" tries to relate the concepts of civilization, empire, and war to one another in such a way that their interaction results in positive feedback loops leading them ever upward and onward in a spiraling motion, unless and until it leads them in the opposite direction by way of negative feedback loops which reverse the direction of the spiral." (Eckhardt, 1995:75)

As a matter of terminology, a vicious cycle or downward spiral is usually also termed a "positive feedback loop," since it is a same-sign causal loop. In any case, Eckhardt postpones discussion of it to later publications. His analysis uses time series data on civilizations (measured by Kroeber's geniuses), empires (measured by Taagepera's territorial size), and wars (battles) to argue that variations in these over time are highly intercorrelated and to show an (exponential) increase in these variables over three millennia. This is certainly consistent with a self-reinforcing, autocatalytic process of accumulation and domination.

There are some limitations of Eckhardt's model specifications and historical data. Correlations and factor analyses are weak evidence of causal connections, since it is notorious that variables often tend to move together over time even when there are no causal connection among them. Moreover, when the data are historical mentions (of, say, battles), there is the further problem that historians' mentions of anything - rats, clouds or sexual peccadilloes - are often a function of the gross volume of historical analysis focused upon a period or a group. 
[Page 95]

Joumal of World-Systems Research

Moreover, Eckhardt's analysis is only dialectical in a limited sense. No qualitative changes are posited over the entire three millennia, but merely an invariant correlation of civilizations, empires and wars. It would appear that the relevant question is whether or not the social dynamic has changed. Nevertheless, the virtue of Eckhardt's analysis is that it links the concepts of dialectics and positive feedback.

From the standpoint adopted here, there are three main implications of the selfreinforcing processes plausibly involved in this transformation:

- The dynamics of development also generate inequality within and between the political units.

- Development tends to collide with external and internal limits.

- At the limit of expansion, positive feedback loops are transformed from a beneficent cycle of development to a vicious cycle of collapse.

Self-reinforcing processes are powerful analytical tools in accounting for long term social developments and their possible branches. If groups with one kind of resource are in a strong position to acquire other resources, the result is a dynamic that generates accumulation, inequality and polarization. Moreover, the same dynamic that generates expansion insures that limits to that expansion produce an inherently unstable situation, and collapse or contraction.

[Page 96]

Journal of World-Systems Research

There are at least two bodies of analysis that such a theory can mobilize and integrate. The first is the burgeoning analysis of the dynamics of complex non-linear systems. The second is the older body of dialectical historical and political analyses. The idealism and obscurantism of many of Hegel's constructions is well known. But whatever else he was, Hegel was an erudite historian and systematic thinker who was extremely sensitive to self-reinforcing processes of accumulation and to their tendency to produce polarization and conflict. His cultural, political and historical analyses have been extended, since then, by Marxist thinkers. Recast in systems terms, even torturous forms of argument from the Philosophy of History, which are utterly inadequate as theory, are immensely interesting theoretically as outcomes to be explained. For example, the great overall structure of that work pictures a "world spirit" that undergoes a discontinuous development with geographical displacements. After a rhythmic development in one area, such as Persia, the "world spirit" takes a flying leap to another, such as Greece. We are only now in a 
position to theoretically grasp and empirically analyze the kinds of discontinuity and geographical displacement to which such Hegelian dialectical analyses drew attention.

\section{Conclusion}

It has been remarked that all theories of history (and hence all macro-dynamic models) boil down to a circle or a line. Evolutionary theories produce lines in the form of directional secular trends. Cyclical theories generate circles, which include the degenerate circle of a point (i.e. arguments that human nature is everywhere the same) and the snow storm of postmodernism (i.e. arguments that all patterns and macro-theories are merely subjective forms of ideological domination). Dialectical theories are often viewed as combining cycles and trends - a cycle leading to an advance and a recapitulation at a higher level - producing a kind of spiral.

[Page 97]

Journal of World-Systems Research

This essay has argued that a common and pervasive form of dynamic system - the positive feedback loop - produces many of the characteristics of dialectical systems. Classical dialectics produced a somewhat portentous apparatus of concepts for analyzing change, such as diremption, contradiction, negation, sublation and limit. Contemporary systems dynamics and analyses of non-linear systems, provide useful tools for analyzing social transformations, and produce systems with discontinuous dynamics that are easily described in terms of dialectical categories. They generate systems that often accomplish accumulation by a dynamic that necessarily creates polarization ("diremption'), and whose historical trajectory may be both forked ("bifurcation") and repeat at a higher level of prior developments. The concepts of limit and contradiction give the essential dynamics of such systems. The marriage of the richness of the traditional concepts of dialectics with the quantitative techniques of contemporary dynamic systems analysis is a promising way to address many contemporary theoretical problems.

\section{Bibliography}

Agresano, J., 1992. The Political Economy of Gunnar Myrdal. Lyme: Chelthenham.

Bar-Yam, Y. 1988. Dynamics of Complex Systems. Reading: Addison-Wesley.

Brown, C., 1995. Chaos and Catastrophe Theories. Beverly Hills: Sage.

Berry, W., 1984. Nonrecursive Causal Models. Beverly Hills: Sage

[Page 98]

Joumal of World-Systems Research 
Burns, T. \& W. Buckley, 1976. Power and Control. Beverly Hills: Sage.

Carneiro, R., 1970. "A theory of the Origin of the Sate," Science 169:733-8.

Chase-Dunn, C., 1989. Global Formation. Oxford: Blackwell.

Cohen, G., 1978. Karl Marx's Theory of History. Princeton: Princeton University Press.

Cole, J. \& B. Singer, 1991. "A Theory of Limited Differences," In H. Zuckerman et al (ed.) The Outer Circle. New York: Norton.

Collins, R., 1992. "What Theories Predicted the Fall of the Soviet Union?" American Sociological Review

Collins, R., R. Hanneman, \& G. Mordt, 1995, "Discovering Theory Dynamics By Simulation," Sociological Methodology 25: 1-46.

Cortes, F., A. Przeworski, \& J. Sprague, 1974 Systems Analysis For Social Scientists. New York: Wiley.

Eckhardt, W., 1995. "A Dialectical Evolutionary Theory of Civilizations," In Sanderson, 1995.

[Page 99]

Journal of World-Systems Research

Engels, F., 1888 "Ludwig Feuerback and the End of Classical German Philosophy," In Marx, K \& Engels, F. Selected Works. New York: International Publishers.

Forrester, J., 1969. Urban Dynamics. Cambridge: MIT Press.

Forrester, J., 1971. World Dynamics. Cambridge: MTT Press.

Gell-Mann, M., 1994. The Quark and the Jaguar. New York: Freeman.

Gleick, J., 1988. Chaos: Making a New Science. New York: Penguin.

Gould, S., 1989. Wonderful Life. New York: Norton.

Hallinan, M., 1997. "The Sociological Study of Social Change," American Sociological Review 62:1-11. 
Hanneman, R., 1988. Computer-Assisted theory Building. Newbury Park: Sage.

[Page 100]

Journal of World-Systems Research

Hanneman, R \& R. Collins, "A Dynamic Simulation of Marx's Model of Capitalism," In wiley, N. (Ed.) The Marx-Weber Debate. Beverly Hills: Sage.

Jensen, A., 1998. The g Factor. Westport: Praeger.

Kauffinan, S., 1993. The Origin of Order. Oxford: Oxford.

Knapp, P., 1994. One World. New York: Harper Collins.

Knapp, P. \& A. Spector, 1991. Crisis and Change. Chicago: Nelson Hall.

Knapp, P., J. Kronick, W. Marks, \& M. Vosburgh, 1996. The Assault on Equality.

Westport: Praeger.

Levin, M., 1997. Why Race Matters. Westport: Praeger.

Levins, R \& R. Lewontin, 1985. The Dialectical Biologist. Cambridge: Harvard University Press.

[Page 101]

Journal of World-Systems Research

Lewin, R., 1992. Complexity: Life at the Edge of Chaos. New York: Macmillan.

Marx, K., 1974 [1867]. Capital. New York: International.

Marx, K. \& F. Engels, 1977. Selected Works. New York: International.

Mayhew, B., 1980 "Structuralism versus Individualism," Social Forces 59: 335-75; 62748.

Merton, R., 1973. The Sociology of Science. Chicago: University of Chicago Press.

Myrdal, G. 1970. Challenge of World Poverty. New York: Pantheon.

Myrdal, G., 1968. Asian Drama. New York: 20th Century Fund. 
Myrdal, G., 1944. American Dilemma. New York: Harper.

Rockmore, T., 1986. Hegel's Circular Epistemology. Bloomington: Indiana University Press.

Rushton, P., 1995. Race, Evolution and Behavior. New Brunswick: Transaction.

[Page 102]

Journal of World-Systems Research

Tayor, J (ed.) The Real American Dilemma. Oklon: New Century.

Sanderson, Stephen 1990 Evolutionism. Cambridge, MA.: Blackwell 1995 Social Transformations. Cambridge, MA.: Blackwell.

Sanderson, Stephen (ed.) 1995 Civilizations and World-Systems. Walnut Creek, CA.: Altamira Press.

Van Parijs, P., 1987. Evolutionary Explanation in Social Science. Totowa: Rowman.

Von Bertalanffy, L., 1968 General Systems Theory. New York: Brazilier.

Weiner, N., 1965. Cybernetics. Cambridge: MIT Press.

Wallerstein, I., 1997. "Social Science and the Quest for a Just Society," American Journal of Sociology 102: 1241-57.

[Page 103]

Journal of World-Systems Research 